\title{
Single-center experience with treatment of cardiogenic shock in children by pediatric ventricular assist devices
}

\author{
Roland Hetzer, MD, PhD, Evgenij V. Potapov, MD, PhD, Vladimir Alexi-Meskishvili, MD, PhD, \\ Yuguo Weng, MD, PhD, Oliver Miera, MD, Felix Berger, MD, PhD, Ewald Hennig, PhD, and \\ Michael Hübler, MD
}

\begin{abstract}
Background: Pediatric ventricular assist devices may be superior to extracorporeal membrane oxygenation in some respects, especially for medium- and long-term cardiac support. We present our nearly 20 -year experience with pediatric ventricular assist devices.
\end{abstract} Methods: Between 1990 and April 2009, Berlin Heart EXCOR (Berlin Heart AG, Berlin, Germany) was im-
planted in 94 children. Patients were compared according to period of treatment: group I, implantation between
1990 and $2001(\mathrm{n}=45)$, and group II, implantation since $2002(\mathrm{n}=49)$.

Results: Preoperative serum creatinine ( $1.2 \mathrm{vs} 0.7 \mathrm{mg} / \mathrm{dL}, P=.002)$ and bilirubin $(1.5 \mathrm{vs} 1 \mathrm{mg} / \mathrm{dL}, P=.002)$ were lower in period II, and fewer patients were artificially ventilated before surgery (26 vs $13, P=.002)$. In period I, more patients were supported with biventricular assist devices $(64 \%$ vs $22.5 \%, P<.001)$. Median time on support was shorter in period I (10 vs 40 days, $P<.001)$. Success (weaning from system or heart transplant) was achieved in $49 \%$ and $69 \%$, respectively $(P=.043)$. Whereas in period I $17 \%$ of children younger than 1 year were discharged home after transplant or weaning, rate during period II was $93 \%(P<.001)$, in particular because of improvement in discharge rate of patients with postcardiotomy heart failure $(13 \% \mathrm{vs} 50 \%)$. Rates of pump exchange for thrombus formation were $0.029 / \mathrm{d}$ in period I and $0.014 / \mathrm{d}$ in period II $(P=0.003)$.

Conclusions: Recent results show significant improvements in survival and discharge rate, especially for children younger than 1 year. Pediatric Berlin Heart EXCOR ventricular assist device may provide a safe mechanical support strategy in children with cardiogenic shock. (J Thorac Cardiovasc Surg 2011;141:616-23)

Supplemental material is available online.

For support of the failing heart in children, modifications of the original heart-lung machine circuit, such as extracorporeal membrane oxygenation (ECMO) $)^{1-3}$ and extracorporeal centrifugal pumps, ${ }^{4}$ have been widely used since the development of pediatric cardiac surgery. Pediatric-size pneumatically driven extracorporeal assist devices for infants and small children were introduced into clinical practice in 1992. The development of such miniaturized pump systems ${ }^{5}$ followed the experience of the first reported pediatric case, in which an 8-year-old patient was supported with an adult-size ventricular assist device (VAD) until later transplant at our institution. ${ }^{6}$ Although pumps for neonates and infants of $10-\mathrm{mL}$ pump volume then became available, in

From Deutsches Herzzentrum, Berlin, Germany.

Disclosures: Authors have nothing to disclose with regard to commercial support.

Received for publication Sept 18, 2009; revisions received May 4, 2010; accepted for publication June 1, 2010.

Address for reprints: Roland Hetzer, $\mathrm{MD}, \mathrm{PhD}$, Deutsches Herzzentrum Berlin, Augustenburger Platz 1, 13353 Berlin, Germany (E-mail: hetzer@dhzb.de). 0022-5223/\$36.00

Copyright $₫ 2011$ Published by Elsevier Inc. on behalf of The American Association for Thoracic Surgery

doi:10.1016/j.jtcvs.2010.06.066 the beginning results in this age group were unfavorable. Until 1998, no patient younger than 1 year was discharged home after such treatment at our institution. ${ }^{7}$ Since then, several improvements have been introduced with regard to system design, postoperative management, and, most importantly, earlier decision making in favor of pump implantation before irreversible shock has set in. We present our experience since 2002 (period II) in comparison with the earlier period of 1990 to 2001 (period I).

\section{MATERIALS AND METHODS}

This analysis is a retrospective study of the use of Conformité Européenne-certified Berlin Heart EXCOR VADs (Berlin Heart AG, Berlin, Germany). Under German law, the retrospective data analysis did not require approval by the ethics committee (in accordance with the Helsinki Declaration of Human Rights). Informed consent to placement of the device was obtained from the parents of all patients.

\section{Patients}

Since 1990, and as of April 1, 2009, Berlin Heart EXCOR systems have been implanted in 94 patients younger than 18 years who had inotropedependent end-stage heart failure, were switched from ECMO support, or had postcardiotomy syndrome. The patients were divided into groups according to the period of treatment: period I represented implantation between 1990 and the end of $2001(\mathrm{n}=45)$, and period II represented implantation between the beginning of 2002 and April 1, 2009 ( $n=49)$. The treatment periods were chosen because after 2001 there were no further modifications of the Berlin Heart pediatric system (Carmeda heparin 


\section{Abbreviations and Acronyms \\ $\mathrm{BNP}=\mathrm{B}$-type natriuretic peptide \\ BVAD $=$ biventricular assist device \\ $\mathrm{ECMO}=$ extracorporeal membrane oxygenation \\ LVAD $=$ left ventricular assist device \\ $\mathrm{VAD}=$ ventricular assist device}

coating [Carmeda $\mathrm{AB}$, Upplands Väsby, Sweden], improvements in the aortic cannulas), of implantation techniques (left apical vs atrial cannulation; Figure 1), or of perioperative management (anticoagulation). In addition, several subgroups were analyzed according to age, diagnosis, and mode of support (univentricular vs biventricular). Treatment was considered successful when the patient survived until a heart transplant was performed, the patient was weaned from the system, which was explanted, or the patient was discharged home.

\section{The Berlin Heart System}

The Berlin Heart EXCOR VAD consists of a paracorporeal, pneumatic, compressor-operated diaphragm pump with polyurethane valves (stroke volumes 10,25 , and $30 \mathrm{~mL}$ ). The larger pumps $(50,60$, and $80 \mathrm{~mL}$ ) were equipped with mechanical valves (Sorin S.p.A., Milan, Italy). In all pumps, silicone cannulas were used. The fairly large Ikus driving unit (Berlin Heart) may be used with all pumps and in all situations; when driving pressures lower than $250 \mathrm{~mm} \mathrm{Hg}$ were required, the EXCOR mobile driving unit (Berlin Heart) was used with pumps of 50,60 , or $80 \mathrm{~mL}$. The blood pumps were available in both periods with volumes of 10, 25, 30, 50, 60, and $80 \mathrm{~mL}$. In period I, in addition, modified pumps with 12- and $15-\mathrm{mL}$ stroke volumes were applied in some cases. The system has been described in detail previously. ${ }^{8-10}$ The pediatric EXCOR device has not been approved by the U.S. Food and Drug Administration for use in the United States and is limited to investigational use under an approved investigational device exemption. The device may also be assessed under the compassionate use regulations, with Food and Drug Administration approval granted on a case by case basis.

\section{Criteria for VAD Implantation}

Criteria for VAD implantation changed with time, tending toward earlier implantation before significant multiorgan failure occurs or after a few days of ECMO to avoid coagulation disorders and infection. The criteria applied were as follows: rapid deterioration of the circulation (cardiac index $<2.0 \mathrm{~L}$ $\min \cdot \mathrm{m}^{2}$ ) with dependence on inotropes, especially epinephrine; critical peripheral perfusion with development of metabolic acidosis and mixed venous saturation less than $40 \%$; signs of beginning renal, hepatic, and respiratory failure (patient on respirator with mounting inspired oxygen fraction); and, most recently, high or rapidly increasing B-type natriuretic peptide (BNP) or N-terminal pro-BNP level. There are no defined cutoff values; the decision was influenced by the rate of clinical deterioration.

\section{Anticoagulation During Device Support}

The current strategy at our institution is as follows: In standard cases, anticoagulation is performed with unfractionated heparin. The effect is closely monitored (2-4 times daily, depending on the clinical situation and the response of the coagulation system of the patient) by measurement of activated partial thromboplastin time with a target of 60 to 80 seconds. Thromboelastography helps to identify the coagulation status and impact of heparin. Antithrombin III should also be closely monitored and substituted if the level falls below $70 \%$. We have continuously improved our anticoagulation management, and since 2007 children remaining in hospital with VAD support have received low-molecular weight heparin for long-term anticoagulation under monitoring of anti-Xa activity, as described by Ghez and colleagues. ${ }^{11}$ The target anti-Xa activity is set at between 1.0 and $1.2 \mathrm{IU} / \mathrm{mL}$. After treatment with acetylsalicylic acid and dipyridamole has been initiated (after the start of oral feeding and the removal of chest tubes and in a dose adjusted to patient weight), platelet aggregation tests are performed at least weekly, with target activation of $30 \% .{ }^{12}$ In patients with heparin-induced thrombocytopenia type II, L-hirudin or argatroban is used. ${ }^{13}$ Adolescents who are discharged home with VAD support receive phenprocoumon with a target international normalized ratio of 3 to 3.5 .

\section{Weaning Criteria}

Weaning was considered for patients with continuous improvement in myocardial function and appropriate wall thickness changes, as measured by daily echocardiography in all patients. Pulmonary pressure was monitored in larger patients by pulmonary catheter and in smaller children by echocardiography. No dobutamine stress echocardiography was performed. The pump flow was then decreased, and blood pressure and ventricular filling were observed. Echocardiographic studies (conventional echocardiography plus tissue Doppler and strain imaging) were performed during a pump stop lasting not more than 30 minutes, while an additional heparin dose was administered (70-100 IU/kg body weight), and the pump
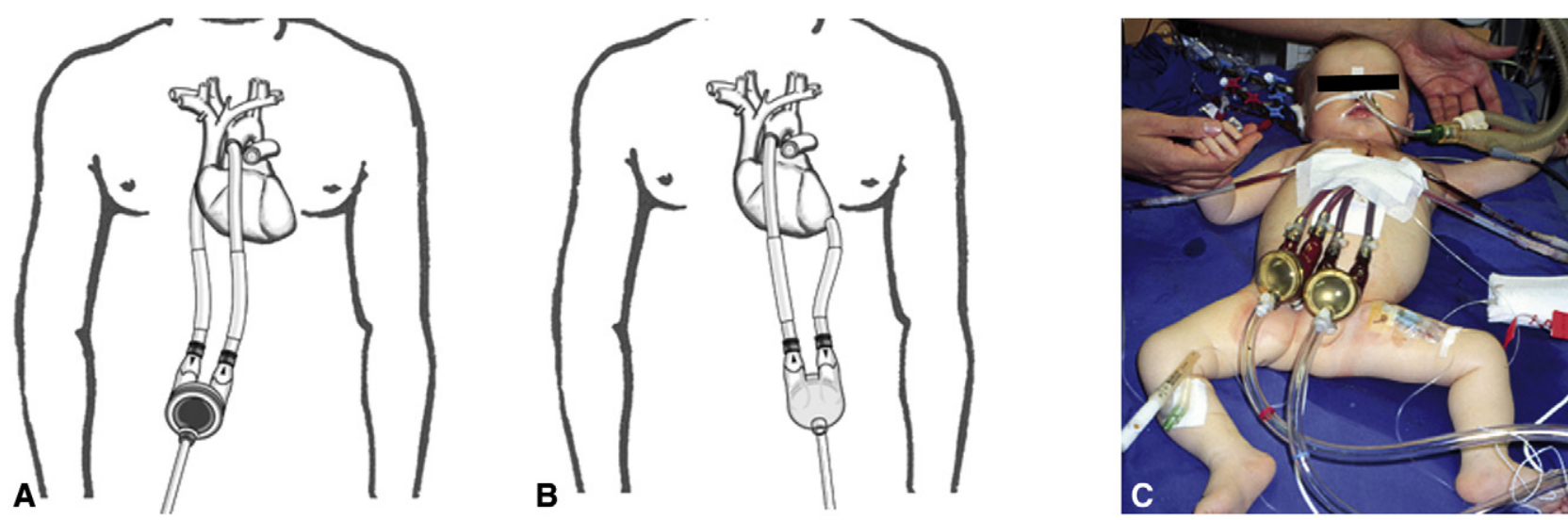

FIGURE 1. Implantation of pediatric Berlin Heart VAD in left and biventricular modes. Inflow cannula is implanted into left atrium (A) or apex of left ventricle (B). Left apical implantation is preferred because it provides better unloading of left ventricle. Implantation is also possible in biventricular mode $(\mathrm{C})$. 
system was operated manually (1-2 times every 30 seconds) to avoid thrombus formation.

Weaning was decided on and performed when, during repeated pump stops (usually 3-4) without any inotropic support, left ventricular ejection fraction remained stable at greater than $45 \%$, left ventricular end-diastolic diameter also remained stable at around the $97 \%$ percentile of age-related index value, and, if appropriate, mitral valve regurgitation did not worsen. Additionally, stable central venous saturation and low pulmonary arterial pressure (estimated by echocardiography) during pump stops were considered to be good prognostic parameters, as was normalization of the level of BNP or N-terminal pro-BNP during the entire weaning period. In some cases of suspected myocarditis or unclear diagnosis, an additional biopsy was helpful.

The weaning protocol was the same for different pump sizes. Weaning was considered successful if the patient had stable myocardial function throughout the first year after device explantation.

\section{Discharge Home With Berlin Heart System}

Small children dependent on the stationary Ikus driver were kept in the hospital with a continuous heparin infusion (except patients treated with low-molecular weight heparin). Discharge home with VAD support is allowed in Germany, and older children for whom the portable EXCOR driver could be operated were discharged home whenever possible, receiving anticoagulation with vitamin $\mathrm{K}$ antagonist (monitored with home use of an international normalized ratio measurement device) and acetylsalicylic acid (monitored by platelet aggregation tests performed at ambulatory visits). These children went to school with the device. Details of the outpatient management have been described by Drews and associates ${ }^{14}$ from our working group.

\section{Statistical Analysis}

The statistical analysis was performed with the SPSS version 12.1 software package for Windows (SPSS Inc, an IBM Company, Chicago, Ill). For continuous data, means and SDs or medians and ranges were calculated. Categoric data are reported as relative frequencies and percentages. The Mann-Whitney $t$ test or $\chi^{2}$ test was applied to test differences between treatment periods. A cumulative sum plot was constructed to show the impact of the various changes on mortality (Figure E1).

\section{RESULTS}

The preoperative data are shown in Table 1. There were no statistically significant differences in sex, age, or weight between the study periods. In the early period, more patients received implantation during mechanical ventilation or after cardiopulmonary resuscitation. This and the elevated serum creatinine reflect the fact that patients in the earlier period were sicker at the time of implantation.

There were fewer biventricular assist devices (BVADs) implanted in the later treatment period $(64 \%$ vs $22.5 \%$, $P<.001$ ), in favor of more left VADs (LVADs; Figure 1). The median duration of VAD support was significantly shorter in period I than in period II (10 vs 40 days, $P<.001)$.

\section{Diagnoses Before VAD Implantation}

Table 2 shows the diagnoses in patients who underwent VAD implantation. The largest cohort represents patients with dilated cardiomyopathy and endomyocardial fibrosis, with increasing numbers in the later period $(17,38 \%$, vs $29,59 \%, P=.038$ ). The next largest population was patients with viral myocarditis, with fewer children treated in period II $(10,22 \%$, vs $6,12 \%)$. The proportions of patients with decompensated congenital heart defects was similar in the two periods $(9,20 \%$, vs $6,12 \%)$; there were 4 patients late after Senning or Mustard procedure in period I but none in period II (Table E1). The proportion of patients requiring VAD after cardiac surgery decreased slightly in the later period $(8,18 \%$, vs $6,12 \%$, difference not significant). Acute graft failure was a reason for VAD implantation in 1 child in the earlier period and in 2 in the later period. The outcome related to diagnosis in the two time periods is given in Figure 2, $B$.

\section{Outcome}

There were no cases of fatal technical failure of the device, such as malfunction of the pump components or driving system, in either treatment period.

The outcomes in period I (45 patients) and period II (49 patients) were weaning $(5,11 \%$, vs $11,22.5 \%, P=.14)$,

TABLE 1. Preoperative patient data and type and duration of support

\begin{tabular}{|c|c|c|c|}
\hline Preoperative data & $\begin{array}{c}\text { Period } I \\
(1990-2001, n=45)\end{array}$ & $\begin{array}{c}\text { Period II } \\
(2002-2009, n=49)\end{array}$ & $P$ value \\
\hline Sex (male/female) & $24: 21$ & $25: 24$ & NS \\
\hline Age (y, median and range) & $7(0-17)$ & $6(0-17)$ & NS \\
\hline Weight (kg, median and range) & $22(2.2-115)$ & $19(3.6-80)$ & NS \\
\hline Cardiopulmonary resuscitation (no.) & 20 & 14 & NS \\
\hline Ventilator (no.) & 26 & 13 & .002 \\
\hline Extracorporeal membrane oxygenation (no.) & 2 & 7 & NS \\
\hline Serum creatinine (mg/dL, median and range) & $1.19(0.2-3.01)$ & $0.7(1.2-3.96)$ & .002 \\
\hline Serum bilirubin (mg/dL, median and range) & $1.53(0.4-13.28)$ & $1(0.17-7.14)$ & NS \\
\hline \multicolumn{4}{|l|}{ Type of support (no.) } \\
\hline Left ventricular & 15 & 37 & $<.001$ \\
\hline Biventricular & 30 & 11 & \\
\hline Right ventricular & 0 & 1 & \\
\hline Time on support ( $d$, median and range) & $10(0-111)$ & $40(0-420)$ & $<.001$ \\
\hline
\end{tabular}

NS, Not significant. 
TABLE 2. Diagnosis before implantation of ventricular assist device

\begin{tabular}{lcc}
\hline & $\begin{array}{c}\text { Period I } \\
(\mathbf{1 9 9 0 - 2 0 0 1 ,} \\
\mathbf{n = 4 5 )}\end{array}$ & $\begin{array}{c}\text { Period II } \\
(\mathbf{2 0 0 2}-\mathbf{2 0 0 9}, \\
\mathbf{n = 4 9 )}\end{array}$ \\
\hline Cardiomyopathy & 17 & 29 \\
$\quad$ Dilative & 16 & 24 \\
Toxic & 1 & 1 \\
$\quad$ Restrictive & - & 3 \\
Myocarditis & 10 & 6 \\
End-stage congenital heart disease & 8 & 6 \\
Postcardiotomy heart failure & 9 & 6 \\
Graft failure after heart transplant & 1 & 2 \\
\hline D
\end{tabular}

Data represent number of patients.

heart transplant $(17,38 \%$, vs $23,47 \%, P=.37)$, and death (23, $51 \%$, vs $14,29 \%, P=.043) ; 1$ patient in period II was still receiving support. Seventeen $(38 \%)$ patients were extubated while supported by the device during period I and 39 $(80 \%)$ during period II $(P=.063)$. In the early period, 2 of 12 of the infants younger than 1 year $(17 \%)$ were successfully treated, whereas in the later period this proportion increased to 14 of $15(93 \%, P<.001)$. Treatment of the children aged between 1 and 8 years was successful in $64 \%$ of cases in the earlier period and $40 \%$ in the later period, and treatment of the children older than 8 years was successful in $59 \%$ and $67 \%$ of cases in periods I and II, respectively (Figure 2,A). The difference in outcome was not statistically significant.

According to the preoperative diagnosis, there was a 3-fold increase in the discharge rate in period II in patients with postcardiotomy heart failure, although statistical significance was not reached $(13 \%$ vs $50 \%, P=.12$; Figure 2, $B$ ). See also the cumulative sum plot (Figure E1).

\section{Weaning}

Sixteen patients were weaned from the VAD. Most of these children had myocarditis $(n=7), 3$ patients were successfully weaned after correction of congenital heart disease, 3 had dilated cardiomyopathy, 1 had noncompaction myocardium, 1 had decompensated heart failure with Ebstein anomaly, and 1 had acute graft failure. There was 1 early death immediately after weaning and 1 at 2.5 years later. One patient underwent heart transplant during follow-up; no further recurrence of heart failure was noted. The data are presented in Table 3. There were no long-term complications after removal of the left ventricular cannula. The incision of the apex of the left ventricle does not, in our opinion, cause future ventricular arrhythmias or impair left ventricular function as long as injury of the main coronary arteries is avoided.

\section{Bridge to Heart Transplant}

In period I 17 children (38\%) and in period II 40 children $(82 \%)$ were bridged to heart transplant with a VAD. In the

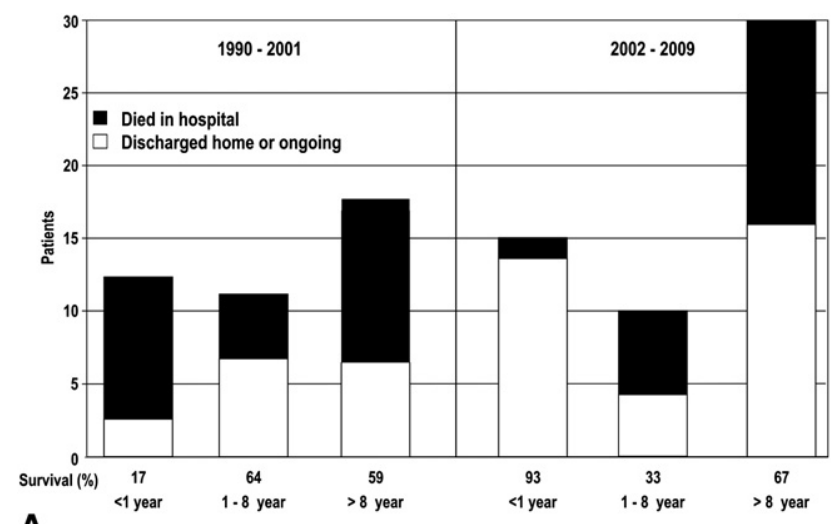

A

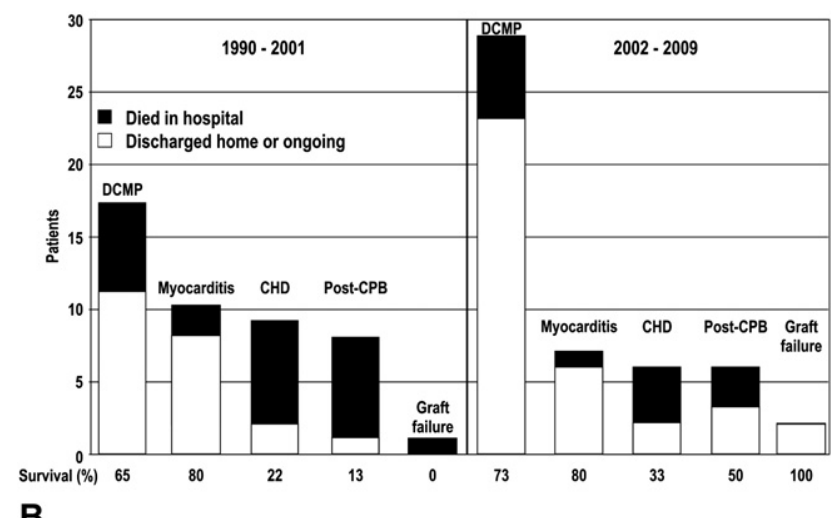

FIGURE 2. A, Survivals in different age categories in both periods. B, Hospital discharge rates for different indications for VAD support in both treatment periods. Note significant improvement for cardiomyopathy and postcardiotomy heart failure in second period. DCMP, dilated cardiomyopathy; $C H D$, congenital heart disease; post- $C P B$, postcardiotomy heart failure.

same total study period, a total of 156 pediatric transplants were performed at our institution. There was no difference in long-term survival between children with primary transplants and children bridged to heart transplant by VAD. The Kaplan-Meier survival data showed no significant differences in survival between the 2 groups (Figure E2).

\section{Complications}

In the earlier period 14 re-explorations for bleeding were necessary in 10 patients ( $22 \%$ ), compared with 11 in 11 patients $(22 \%)$ in the later period. In the earlier period 25 pumps were exchanged in 13 patients, and in the later period 46 pumps were exchanged in 19 patients. The pump exchange rate of 0.029 per day in period I was reduced to 0.014 per day in period II $(P=.003)$. In the second period, however, 12 pump exchanges were performed during a 3-month period in a single patient with heparin-induced thrombocytopenia type II (for calculations, 1 day of BVAD support was counted as 1 pump day). There were 3 cases of cerebral vascular accident resulting in fatality or residual deficit in period I (cumulative days on support 869), 
TABLE 3. Patients weaned from ventricular assist device

\begin{tabular}{lccllcl}
\hline Case & Age $(\mathbf{y})$ & Weight $(\mathbf{k g})$ & Diagnosis & Pumps & Support time (d) & Outcome \\
\hline 1 & 5 & 16 & Myocarditis & $30 / 25$ & 22 & Weaned, alive \\
2 & 6 & 23 & Myocarditis & $30 / 25$ & 11 & Weaned, death 2.5 y later \\
3 & 1 & 10 & Myocarditis & $30 / 25$ & 11 & Weaned, alive \\
4 & 1 & 9 & Myocarditis & $30 / 25$ & 10 & Weaned, alive \\
5 & 14 & 37 & DCMP & $60 /-$ & 22 & Weaned, alive \\
6 & 4 & 17 & Ebstein & $30 / 25$ & 17 & Bidirectional caval pulmonary \\
& & & & & 6 & Weastomosis, tricuspid valve repair \\
7 & 0.4 & 4 & CAVSD & $10 /-$ & 11 & Weaned, alive \\
8 & 0.3 & 5 & ALCAPA & $10 /-$ & 12 & Weaned, alive \\
9 & 0.3 & 4 & ALCAPA & $10 /-$ & 77 & Weaned, alive \\
10 & 16 & 49 & HTx failure & $50 /-$ & 120 & Weaned with bone marrow \\
11 & 14 & 55 & DCMP & $80 /-$ & & transplant, alive \\
& & & & & 41 & Weaned, alive \\
12 & 0.5 & 7 & Myocarditis & $10 /-$ & 29 & Weaned, alive \\
13 & 0.4 & 6 & Myocarditis & $10 /-$ & 62 & Weaned, alive \\
14 & 0.25 & 4 & Noncompaction & $10 /-$ & 35 & Weaned, alive \\
15 & 0.05 & 3.5 & Myocarditis & $10 /-$ & 17 & Weaned, early cerebral death \\
16 & 0.6 & 8 & DCMP & $10 /-$ & & \\
\hline
\end{tabular}

Patients 1 to 5 were weaned in period I and patients 6 to 16 in period II. Outcome status is presented as of March 1, 2009. Supplemental material is available online. DCMP, Dilated cardiomyopathy; $C A V S D$, complete atrioventricular defect; $H T x$, heart transplant; $A L C A P A$, anomalous left coronary artery origin from pulmonary artery.

compared with 6 in period II (cumulative days on support $3303)$.

\section{Death During Device Use}

Significantly fewer patients died while supported by the device in period II $(23,51 \%$, vs $14,29 \%, P=.043)$. The main reasons for death in both periods were multiorgan failure $(\mathrm{n}=13)$ and cerebrovascular accident after hemorrhage or ischemia $(\mathrm{n}=10$, including 1 patient with cerebral damage before VAD implantation). Vasoplegic shock was the cause of death in 5 cases, and lung failure and sepsis were the cause of death in 3 cases each. In 2 cases, bleeding after dislodgment of cannulas (both patients boys with BVADs, aged 6 and 11 years, 13 and 2 days on support) caused death, and in 1 case, perforation of the left ventricle during placement of a chest drain (girl aged 16 years with LVAD, 5 days on support) caused death.

\section{DISCUSSION}

The pediatric Berlin Heart EXCOR VAD is the most widely used long-term system worldwide for the treatment of children of all ages with heart failure. This report documents our experience with this system from its introduction into clinical use through several steps of system changes and insights concerning system application that our team worked out together with the Berlin Heart company. Since the first experience with a child supported by a Berlin Heart VAD ${ }^{6}$ and the subsequent development of miniaturized systems for children and infants (since 1992), substantial changes have been introduced into clinical decision making and patient care, ${ }^{9}$ and modifications have been made to the system itself. These modifications have led to improved survival and, consequently, longer support times in recent years, especially for neonates and small infants. These advances have made the Berlin Heart system a fairly mature tool to treat severe heart failure successfully in this group of patients. Additionally, increased waiting time for heart transplants has contributed to the prolongation of the time on mechanical support. Some of our earlier publications have presented analyses of these developments on the basis of studies of small numbers of patients ${ }^{9}$; here, we have focused on the analysis of our whole experience with almost 100 patients, the largest number reported in a single-center study.

The Berlin Heart system has proved to be able to keep children alive to be bridged to transplant during long periods with good outcome. ${ }^{15}$ Such a prolonged support time has allowed a child being treated for malignancy ${ }^{16}$ to reach transplantable status by documentation of a sufficiently long tumor-free period to justify listing for heart transplant. Similarly, transplantable status may be reached after prolonged support in children with adequate regression of preoperatively elevated pulmonary vascular resistance. ${ }^{17}$

Since 1988, close to 9000 operations for congenital heart defects and more than 150 pediatric transplants have been performed at our institution. Centrifugal pumps and ECMO also have their place in our pediatric program, especially for patients with the potential for fast myocardial recovery and expected short-term support. ${ }^{18,19}$ In contrast to patients supported with these devices, those with the Berlin Heart VAD can be mobilized, extubated, and fed orally, which is advantageous when waiting periods longer than 3 or 4 weeks must be anticipated. ${ }^{3,20,21}$ Eight patients were supported by ECMO before VAD implantation, with 
a discharge rate of $60 \%$, in period II. The decision to switch from ECMO to VAD was taken when it became clear that longer-term support was needed and the patient had not suffered severe damage, particularly to the brain, before or during ECMO. Another indication for VAD implantation was continuous bleeding on ECMO, because of the lower anticoagulation required on $\mathrm{VAD}$, in particular in cases of open ECMO. A switch from ECMO to pediatric Berlin Heart EXCOR has also been described ${ }^{22}$ and the Berlin Heart pediatric system allows children to be bridged to transplant through long waiting periods. ${ }^{15}$ In contrast to patients with ECMO support, those with VAD support required less transfusion of blood products, with correspondingly decreased risks of infection and of development of HLA antibodies. $^{23,24}$ The advantages of long-term VAD support, also in terms of a better cost-effectiveness ratio and of the quality-adjusted life years saved, ${ }^{25}$ have been recognized, and an increasing number of centers are now using this type of support system for children. ${ }^{26-30}$

Application of the Medos VAD (MEDOS Medizintechnik AG, Stolberg, Germany), which is also available for small children, has been reported to be successful with shorter support times. ${ }^{31}$ The use of adult-type long-term implantable LVADs, such as the HeartMate I and II (Thoratec Corporation, Pleasanton, Calif), Ventracor, ${ }^{32}$ or MicroMed DeBakey VAD (MicroMed Cardiovascular, Inc, Houston, Tex), is limited to children weighing more than 15 to $20 \mathrm{~kg}$. ${ }^{21,33-37}$

In our series, there were no patients with persistent intracardiac shunts implanted with the Berlin Heart VAD, because regulation of the pump flow and the patient circulation, systemic and pulmonary, is extremely difficult. Such patients were treated with ECMO if needed. There have been some reports of successful use of the Berlin Heart EXCOR VAD for single-ventricle physiology, ${ }^{38-40}$ however, and in some cases with aortopulmonary shunts. ${ }^{38}$ In children who have undergone staged single-ventricle palliation, including Norwood stage 1 procedure, bidirectional cavopulmonary anastomosis, and repair of obstructed pulmonary veins, the VAD could be used without an oxygenator while keeping the aortopulmonary shunt open and maintaining high pump flows. Clipping of the shunt seems to be unnecessary. ${ }^{41}$

As with any kind of support system, making the decision in favor of earlier implantation has yielded better results. This effect was most pronounced among patients younger than 1 year. During the earlier period, most of these patients started support with the system in a state of advanced circulatory failure, characterized by irreversible organ shock sequelae and unresponsiveness of the peripheral circulation to $\alpha$-stimulants, so-called vasoplegia. Consequently, in period I no patient younger than 1 year survived for longer than 30 days after VAD implantation, whereas more than three quarters of the infants could finally leave the hospital alive after a policy of earlier placement of the system had been established.
The introduction into the pediatric field of the criteria that have become well established in the adult population (VAD implantation before shock organ failure sets in or, at the latest, at the very first signs of such organ failure ${ }^{3,42-46}$ ) has fulfilled its promise of better survival. At present, we adhere to the criteria given in the Methods section, whereby the speed of deterioration plays an important role.

We strongly believe that, with more confidence in the system, these criteria will be applied less restrictively in the future. Increased survival, however, and the fact that more patients were treated with an LVAD alone, were extubated while supported by the VAD and did not require delayed sternum closure, indicates the positive effects of using these criteria.

Earlier decision making for mechanical circulatory support is most important in the patients after cardiopulmonary bypass. During period I, in most cases this decision was made after protracted courses in the intensive care unit, often after repeated cardiopulmonary resuscitation. There was only one long-term survivor among the patients supported by a VAD under these circumstances. Now, with a staged concept of immediate ECMO installation and later VAD implantation when it becomes apparent that the cardiac function cannot be stabilized postoperatively, such catastrophic courses have been avoided. A similar concept is applied for decompensated chronic heart failure requiring resuscitation. This strategy is evident in the significantly increased number of patients supported by ECMO before VAD implantation (Table 1). In patients with chronic end-stage heart failure, measurement of levels of natriuretic peptides and markers of inflammation offers improved prediction of the optimal time points for VAD implantation and weaning. ${ }^{47}$

In our pediatric population, the sex distributions were similar in the early and late periods. In the adult population, approximately $80 \%$ patients are male. ${ }^{48}$ This phenomenon supports the impact of sex on the incidence, diagnosis, and treatment of heart failure.

Apical drainage has made it more likely that the circulation can be sustained with LVAD support alone, whereas with atrial drainage, BVAD support more often became inevitable. In contrast to our practice, Gandhi and associates ${ }^{27}$ showed that BVAD support offers an additional means of improving postoperative course and reversing extremely elevated pulmonary vascular resistance and can be used effectively in small children as a bridge to heart transplant, with low mortality and morbidity. ${ }^{27}$ Although we now have good results with the LVAD alone, we primarily use a BVAD in cases of profound cardiogenic shock or acute rejection and in such special situations as cases of large cardiac tumors.

Despite significant progress, anticoagulation and its monitoring remain a major problem..$^{12,24,49-52}$ Heparin coating alone has not solved all the problems. In both periods, pumps had to be exchanged when significant thrombus formation became visible, although this rate significantly decreased during period II. In addition, the 
rate of cerebrovascular accidents with fatality or residual deficits, calculated per day of support, was reduced by $50 \%$ in the later period.

The anticoagulation regimen that we currently use has been described in detail. ${ }^{9,13,24,53}$ In 1 particular case, after a frustrating period during which multiple pump thrombi were seen despite intravenous unfractionated heparin, we switched to low-molecular weight heparin with monitoring of anti-Xa activity. Since then, 3 other children requiring long-term anticoagulation during VAD support have been treated with low-molecular weight heparin, allowing a more stable level of anticoagulation without thromboembolic events. The successful long-term use of low-molecular weight heparin has already been described, and it may be a promising alternative to intravenous heparin in some cases. ${ }^{54,55}$ The role of new oral anticoagulants also needs further evaluation.

In contrast to our experience, several groups from the United States have reported frequent neurologic events. These authors have recommended that device exchange at the bedside be considered at the earliest visualization of thrombus formation. ${ }^{26,56}$ Our current criteria for pump exchange are any thrombus formation in the left pump or in the left cannulas and thrombus of more than a few millimeters or freefloating thrombi of any size in the right pump and cannulas.

The durability of all the currently available VADs is limited to a number of years. Therefore, in children and young adults with end-stage heart failure and contraindications for heart transplant, such as high pulmonary vascular resistance or uncertain freedom from malignancy after tumor treatment, there are no long-term options available. In these cases the VAD may bridge children to the status of transplantability, and more children will require long-term support. ${ }^{16,17}$ For such long-term support, smaller and implantable devices would be a better choice in terms of quality of life than extracorporeal devices, such as the Berlin Heart EXCOR.

All axial-flow devices available for commercial use in Europe may be used in older children for long-term support. Except for a small number of MicroMed DeBakey VAD ${ }^{57}$ and Ventracor ${ }^{32}$ implantations, including 1 in a 6-year-old girl, ${ }^{35}$ there have been no reports of such cases as yet. We implanted the axial-flow adult Berlin Heart Incor LVAD in a 17 -year-old adolescent.

The US National Heart, Lung, and Blood Institute is supporting 5 programs for the development of pediatric circulatory support devices. ${ }^{58}$ The devices are expected to be ready for clinical studies in 2009. Only some of these pumps, however, such as the Jarvik 2000 for infants (Jarvik Heart, Inc, New York, NY), have as yet been tested in initial animal studies. ${ }^{59,60}$

\section{Limitations}

This study is of a retrospective nature and presents the clinical experience of the center where the system was de- veloped and most of the improvements were introduced. Some aspects of our experience with smaller patient cohorts have been analyzed and published previously. The longterm survival and functional status, as well as the cerebral function and neurodevelopment of the surviving patients, are currently under investigation and could not be included here. The study was not designed to directly compare ECMO and VAD treatments.

\section{CONCLUSIONS}

In our experience, earlier implantation of VADs, heparincoating of the blood pumps, and substantial modifications in cannula design, anticoagulation, and the coagulation monitoring regimen have led to significant increases in survival and in discharge rate, especially among children younger than 1 year and after postcardiotomy heart failure. The pediatric size Berlin Heart EXCOR VAD now offers a valuable option as a bridge to transplant or recovery for children with cardiogenic shock.

We thank Anne Gale, Editor in the Life Sciences (ELS), for editorial assistance, and we thank Katharina Hoffmann for support with data acquisition.

\section{References}

1. Mehta U, Laks H, Sadeghi A, Marelli D, Odim J, Alejos J, et al. Extracorporeal membrane oxygenation for cardiac support in pediatric patients. Am Surg. 2000; 66:879-86.

2. Bartlett RH, Gazzaniga AB, Jefferies MR, Huxtable RF, Haiduc NJ, Fong SW. Extracorporeal membrane oxygenation (ECMO) cardiopulmonary support in infancy. Trans Am Soc Artif Intern Organs. 1976;22:80-93.

3. del Nido PJ, Armitage JM, Fricker FJ, Shaver M, Cipriani L, Dayal G, et al. Extracorporeal membrane oxygenation support as a bridge to pediatric heart transplantation. Circulation. 1994;90(5 Pt 2):II66-9.

4. Karl TR, Horton SB, Brizard C. Postoperative support with the centrifugal pump ventricular assist device (VAD). Semin Thorac Cardiovasc Surg Pediatr Card Surg Аnпu. 2006;83-91.

5. Hennig E. Design criteria for pediatric mechanical circulatory support systems (PMCSS). In: Ferrazzi P, Parenzan L, eds. Annals of the concerted action HEART 1991-1992. Bergamo, Italy: Commission of the European Communities; 1991:39-43.

6. Warnecke H, Berdjis F, Hennig E, Lange P, Schmitt D, Hummel M, et al. Mechanical left ventricular support as a bridge to cardiac transplantation in childhood. Eur J Cardiothorac Surg. 1991;5:330-3.

7. Hetzer R, Loebe M, Potapov EV, Weng Y, Stiller B, Hennig E, et al. Circulatory support with pneumatic paracorporeal ventricular assist device in infants and children. Ann Thorac Surg. 1998;66:1498-506.

8. Potapov EV, Stiller B, Hetzer R. Ventricular assist devices in children: current achievements and future perspectives. Pediatr Transplant. 2007;11:241-55.

9. Hetzer R, Alexi-Meskishvili V, Weng Y, Hübler M, Potapov E, Drews T, et al. Mechanical cardiac support in the young with the Berlin Heart EXCOR pulsatile ventricular assist device: 15 years' experience. Semin Thorac Cardiovasc Surg Pediatr Card Surg Ann. 2006;99-108.

10. Merkle F, Boettcher W, Stiller B, Hetzer R. Pulsatile mechanical cardiac assistance in pediatric patients with the Berlin heart ventricular assist device. J Extra Corpor Technol. 2003;35:115-20.

11. Ghez O, Liesner R, Karimova A, Ng C, Goldman A, van Doorn C. Subcutaneous low molecular weight heparin for management of anticoagulation in infants on Excor ventricular assist device. ASAIO J. 2006;52:705-7.

12. Potapov EV, Ignatenko S, Nasseri BA, Loebe M, Harke C, Bettmann M, et al. Clinical significance of PlA polymorphism of platelet GP IIb/IIIa receptors during long-term VAD support. Ann Thorac Surg. 2004;77:869-74.

13. Koster A, Huebler S, Potapov E, Meyer O, Jurmann M, Weng Y, et al. Impact of heparin-induced thrombocytopenia on outcome in patients with ventricular assist 
device support: single-institution experience in 358 consecutive patients. Ann Thorac Surg. 2007;83:72-6.

14. Drews TN, Loebe M, Jurmann MJ, Weng Y, Wendelmuth C, Hetzer R. Outpatients on mechanical circulatory support. Ann Thorac Surg. 2003;75:780-5.

15. Cassidy J, Haynes S, Kirk R, Crossland D, Smith JH, Hamilton L, et al. Changing patterns of bridging to heart transplantation in children. J Heart Lung Transplant. 2009;28:249-54.

16. Potapov EV, Weng Y, Jurmann M, Lehmkuhl H, Hetzer R. Bridging to transplantability with a ventricular assist device. J Thorac Cardiovasc Surg. 2005; 130:930.

17. Schulze-Neick I, Luther YC, Ewert P, Lehmkuhl HB, Hetzer R, Lange PE. Endstage heart failure with pulmonary hypertension: levosimendan to evaluate for heart transplantation alone versus combined heart-lung transplantation. Transplantation. 2004; 78:1237-8

18. Alexi-Meskishvili V, Hetzer R, Weng Y, Ishino K, Potapov E, Loebe M, et al. Extracorporeal circulatory support in pediatric cardiac patients-the Berlin Experience. In: Hetzer R, Hennig E, Loebe M, eds. Mechanical circulatory support. Darmstadt, Germany: Springer and Steinkopff; 1997:33-52.

19. Huebler M, Koster A, Redlin M, Boettcher W, Stiller B, Nürnberg I, et al. Repair of ALCAPA in a 4-kg patient followed by successful weaning and "off-pump" explantation of an apical venting pulsatile LVAD. J Card Surg. 2005;20:261-3.

20. Hetzer R, Loebe M, Alexi-Meskishvili V, Stiller B. Pulsatile pediatric assist devices: current results for bridge to transplantation. Pediatr Annu Semin Thorac Cardiovasc Surg. 1999;2:157-76.

21. Hendry PJ, Masters RG, Davies RA, Mesana T, Struthers C, Mussivand T, et al. Mechanical circulatory support for adolescent patients: the Ottawa Heart Institute experience. Can J Cardiol. 2003;19:409-12.

22. Van Doorn C, Karimova A, Burch M, Goldman A. Sequential use of extracorporeal membrane oxygenation and the Berlin Heart Left Ventricular Assist Device for 106-day bridge to transplant in a two-year-old child. ASAIO J. 2005;51:668-9.

23. McKenna DH Jr, Eastlund T, Segall M, Noreen HJ, Park S. HLA alloimmunization in patients requiring ventricular assist device support. J Heart Lung Transplant. 2002;21:1218-24.

24. Stiller B, Lemmer J, Merkle F, Alexi-Meskishvili V, Weng Y, Hübler M, et al. Consumption of blood products during mechanical circulatory support in children: comparison between ECMO and a pulsatile ventricular assist device. Intensive Care Med. 2004;30:1814-20.

25. Mahle WT, Ianucci G, Vincent RN, Kanter KR. Costs associated with ventricular assist device use in children. Ann Thorac Surg. 2008;86:1592-7.

26. Rockett SR, Bryant JC, Morrow WR, Frazier EA, Fiser WP, McKamie WA, et al. Preliminary single center North American experience with the Berlin Heart pediatric EXCOR device. ASAIO J. 2008;54:479-82.

27. Gandhi SK, Huddleston CB, Balzer DT, Epstein DJ, Boschert TA, Canter CE. Biventricular assist devices as a bridge to heart transplantation in small children. Circulation. 2008;118(14 Suppl):S89-93.

28. Grady D. Tubes, pump and fragile hope keep a baby's heart beating. New York Times. 2004 Aug 22; Sect. 1

29. Arabía FA, Tsau PH, Smith RG, Nolan PE, Paramesh V, Bose RK, et al. Pediatric bridge to heart transplantation: application of the Berlin Heart, Medos and Thoratec ventricular assist devices. J Heart Lung Transplant. 2006;25:16-21.

30. Laliberté E, Cecere R, Tchervenkov C, Wan C, Bittira B, Calaritis C, et al. The combined use of extracorporeal life support and the Berlin Heart pulsatile pediatric ventricular assist device as a bridge to transplant in a toddler. J Extra Corpor Technol. 2004;36:158-61.

31. Herwig V, Severin M, Waldenberger FR, Konertz W. Medos/HIA-assist system: first experiences with mechanical circulatory assist in infants and children. Int $J$ Artif Organs. 1997;20:692-4.

32. Ruygrok PN, Esmore DS, Alison PM, Finucane KA, McGuinness SP, McGeorge AD, et al. Pediatric experience with the VentrAssist LVAD. Ann Thorac Surg. 2008;86:622-6.

33. Copeland JG, Arabia FA, Smith RG. Bridge to transplantation with a Thoratec left ventricular assist device in a 17-kg child. Ann Thorac Surg. 2001;71:1003-4.

34. El-Banayosy NR, Arusoglu L, Kleikamp G, Minami K, Körfer R. Recovery of organ dysfunction during bridging to heart transplantation in children and adolescents. Int J Artif Organs. 2003;26:395-400.

35. Morales DL, Dibardino DJ, McKenzie ED, Heinle JS, Chang AC, Loebe M, et al. Lessons learned from the first application of the DeBakey VAD Child: an intracorporeal ventricular assist device for children. J Heart Lung Transplant. 2005; 24:331-7.

36. Reinhartz O, Stiller B, Eilers R, Farrar DJ. Current clinical status of pulsatile pediatric circulatory support. ASAIO J. 2002;48:455-9.
37. Undar A, McKenzie ED, McGarry MC, Owens WR, Surprise DL, Kilpack VD, et al. Outcomes of congenital heart surgery patients after extracorporeal life support at Texas Children's Hospital. Artif Organs. 2004;28:963-6.

38. Pearce FB, Kirklin JK, Holman WL, Barrett CS, Romp RL, Lau YR. Successful cardiac transplant after Berlin Heart bridge in a single ventricle heart: use of aortopulmonary shunt as a supplementary source of pulmonary blood flow. J Thorac Cardiovasc Surg. 2009;137:e40-2.

39. Russo P, Wheeler A, Russo J, Tobias JD. Use of a ventricular assist device as a bridge to transplantation in a patient with single ventricle physiology and total cavopulmonary anastomosis. Paediatr Anaesth. 2008;18:320-4.

40. Prêtre R, Häussler A, Bettex D, Genoni M. Right-sided univentricular cardiac assistance in a failing Fontan circulation. Ann Thorac Surg. 2008;86:1018-20.

41. Hoskote A, Bohn D, Gruenwald C, Edgell D, Cai S, Adatia I, et al. Extracorporeal life support after staged palliation of a functional single ventricle: subsequent morbidity and survival. J Thorac Cardiovasc Surg. 2006;131:1114-21.

42. Deng MC, Weyand M, Hammel D, Schmid C, Kerber S, Schmidt C, et al. Selection and management of ventricular assist device patients: the Muenster experience. J Heart Lung Transplant. 2000;19(8 Suppl):S77-82.

43. Deng MC, Loebe M, El-Banayosy A, Gronda E, Jansen PG, Vigano M, et al. Mechanical circulatory support for advanced heart failure: effect of patient selection on outcome. Circulation. 2001;103:231-7.

44. El-Banayosy A, Arusoglu L, Kizner L, Tenderich G, Boethig D, Minami K, et al. Predictors of survival in patients bridged to transplantation with the Thoratec VAD device: a single-center retrospective study on more than 100 patients. J Heart Lung Transplant. 2000;19:964-8.

45. Loebe M, Hennig E, Müller J, Spiegelsberger S, Weng Y, Hetzer R. Long-term mechanical circulatory support as a bridge to transplantation, for recovery from cardiomyopathy, and for permanent replacement. Eur J Cardiothorac Surg. 1997;11(Suppl):S18-24

46. Williams MR, Oz MC. Indications and patient selection for mechanical ventricular assistance. Ann Thorac Surg. 2001;71(3 Suppl):S86-91; discussion S114-5.

47. Heise G, Lemmer J, Weng Y, Hübler M, Alexi-Meskishvili V, Böttcher W, et al. Biomarker responses during mid-term mechanical cardiac support in children. J Heart Lung Transplant. 2008;27:150-7.

48. Potapov EV, Loforte A, Weng Y, Jurmann M, Pasic M, Drews T, et al. Experience with over 1000 implanted ventricular assist devices. J Card Surg. 2008;23: 185-94.

49. Takahama T, Kanai F, Onishi K. Anticoagulation during use of a left ventricular assist device. ASAIO J. 2000;46:354-7.

50. Spanier T, Oz M, Levin H, Weinberg A, Stamatis K, Stern D, et al. Activation of coagulation and fibrinolytic pathways in patients with left ventricular assist devices. J Thorac Cardiovasc Surg. 1996;112:1090-7.

51. Schmid C, Weyand M, Hammel D, Deng MC, Nabavi D, Scheld HH. Effect of platelet inhibitors on thromboembolism after implantation of a Novacor N100_-preliminary results. Thorac Cardiovasc Surg. 1998;46:260-2.

52. Koster A, Loebe M, Sodian R, Potapov EV, Hansen R, Müller J, et al. Heparin antibodies and thromboembolism in heparin-coated and noncoated ventricular assist devices. J Thorac Cardiovasc Surg. 2001;121:331-5.

53. Drews T, Stiller B, Hübler M, Weng Y, Berger F, Hetzer R. Coagulation management in pediatric mechanical circulatory support. ASAIO J. 2007;53:640-5.

54. Camboni D, Schmid C, Rellensmann G, Tjan TD. Enoxiparin for long-term anticoagulation with the pediatric EXCOR left ventricular assist device. Interact Cardiovasc Thorac Surg. 2005;4:561-2.

55. Sandner SE, Zimpfer D, Zrunek P, Steinlechner B, Rajek A, Schima H, et al. Low molecular weight heparin as an alternative to unfractionated heparin in the immediate postoperative period after left ventricular assist device implantation. Artif Organs. 2008;32:819-22

56. Malaisrie SC, Pelletier MP, Yun JJ, Sharma K, Timek TA, Rosenthal DN, et al Pneumatic paracorporeal ventricular assist device in infants and children: initial Stanford experience. J Heart Lung Transplant. 2008;27:173-7.

57. Fraser CD Jr, Carberry KE, Owens WR, Arrington KA, Morales DL, Heinle JS, et al. Preliminary experience with the MicroMed DeBakey pediatric ventricular assist device. Semin Thorac Cardiovasc Surg Pediatr Card Surg Annu. 2006;109-14.

58. Baldwin JT, Borovetz HS, Duncan BW, Gartner MJ, Jarvik RK, Weiss WJ, et al. The National Heart, Lung, and Blood Institute Pediatric Circulatory Support Program. Circulation. 2006;113:147-55.

59. Kilic A, Nolan TD, Li T, Yankey GK, Prastein DJ, Cheng G, et al. Early in vivo experience with the pediatric Jarvik 2000 heart. ASAIO J. 2007;53:374-8.

60. Kirklin JK. Mechanical circulatory support as a bridge to pediatric cardiac transplantation. Semin Thorac Cardiovasc Surg Pediatr Card Surg Annu. 2008;80-5. 


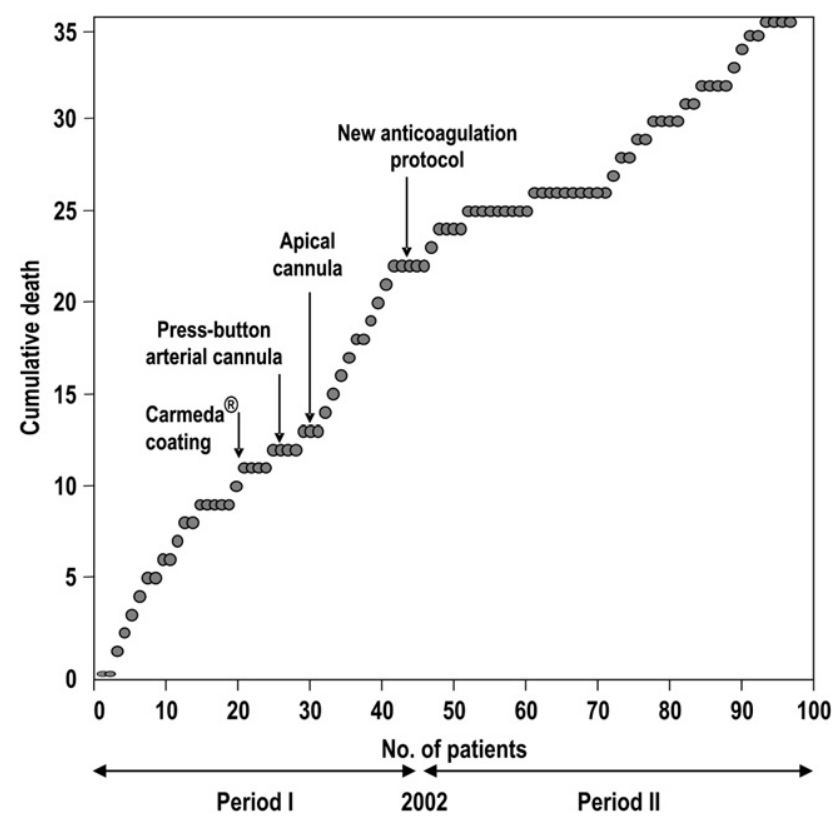

FIGURE E1. Analysis of cumulative mortality in entire population. Important changes in ventricular assist device design, patient selection, and postoperative care are marked in relation to time.

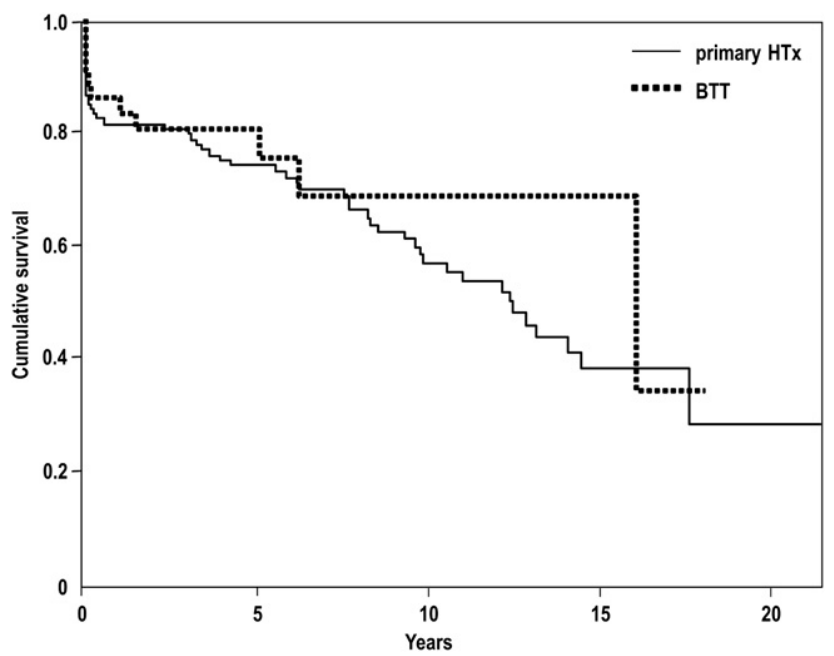

FIGURE E2. Kaplan -Meier analysis for cumulative survival after heart transplant. There was no difference in survival between groups. HTx, Heart transplant; $B T T$, bridge to transplant with ventricular assist device.

TABLE E1. Diagnoses and surgical procedures in patients with congenital heart defects in end-stage chronic heart failure

\begin{tabular}{|c|c|c|c|c|c|c|c|}
\hline Case & Diagnosis and procedures & Age (y) & Weight (kg) & Sex & Pumps & Support (d) & Outcome \\
\hline 1 & Dilatation of AS, CoA & 8 & 27 & M & LVAD & 7 & HTx \\
\hline 2 & Dextro TGA, status post-Mustard & 13 & 51 & $\mathrm{~F}$ & LVAD & 5 & Death \\
\hline 3 & Status post-AVR & 9 & 35 & $\mathrm{~F}$ & BVAD & 1 & Death \\
\hline 4 & PA atresia and coronary sinusoids & $6 \mathrm{~d}$ & 4 & M & LVAD & 2 & Death \\
\hline 5 & Dextro TGA, status post-Senning & 5 & 18.5 & M & BVAD & 13 & Death \\
\hline 6 & Status post tetralogy of Fallot correction, status post-homograft implantation & 15 & 25 & $\mathrm{~F}$ & BVAD & & HTx \\
\hline 7 & Status post-Fontan & 13 & 21 & $\mathrm{~F}$ & LVAD & 1 & Death \\
\hline 8 & TGA, status post-Mustard & 52 & 17 & M & LVAD & 41 & Death \\
\hline 9 & TGA, status post-Senning & 16 & 47 & M & LVAD & 43 & Death \\
\hline 10 & Ebstein anomaly & 4 & 18 & $\mathrm{~F}$ & BVAD & 17 & Recovery \\
\hline 11 & CAVSD, status post-Fontan & 10 & 24 & $\mathrm{~F}$ & LVAD & 15 & Death \\
\hline 12 & VSD, status post-PA banding & 0.4 & 5.4 & M & LVAD & 16 & Recovery \\
\hline 13 & Single ventricle, truncus arteriosus communis, status post-BDCPA anastomosis & 1 & 9 & M & LVAD & 16 & Death \\
\hline 14 & AV stenosis, status post-AVR, -MVRep, and -CABG & 10 & 26 & M & BVAD & 43 & Death \\
\hline 15 & Status postcorrection of HLHS & 4 & 19 & M & LVAD & 26 & Death \\
\hline
\end{tabular}

Patients 1 to 9 were treated in period I and patients 10 to 15 in period II. AS, Aortic stenosis; CoA, coarctation of aorta; $M$, male; $L V A$, left ventricular assist device; $H T x$, heart transplant; TGA, transposition of the great arteries; $F$, female; $A V R$, aortic valve replacement; $B V A D$, biventricular assist device; $P A$, pulmonary artery; $C A V S D$, complete atrioventricular septal defect; $V S D$, ventricular septal defect; $B D C P A$, bidirectional caval pulmonary anastomosis; $M V R e p$, mitral valve repair; $C A B G$, coronary artery bypass grafting; $H L H S$, hypoplastic left heart syndrome. 